\title{
La pasión crítica (Los intelectuales ante el espejo de su tiempo) ${ }^{1}$
}

\section{Sergio Ramírez}

Escritor

Daniel Defoe, igual que José Saramago, comenzó tarde a escribir. Su primera novela, Robinson Crusoe, apareció en 1719, cuando tenía ya la edad de sesenta años, pero de allí en adelante quiso desquitarse del tiempo terco escribiendo con arrebato hasta la hora misma de su muerte. Más allá de haber creado en Robinson uno de los personajes arquetípicos de la literatura de todos los tiempos, se propuso escribir, con pulso de viejo que ya venía de vuelta, historias que sonaran verídicas en los oídos y lo parecieran a los ojos, y para ello utilizó la precisión fría del notario que inventaría bienes en subasta, o del maestro de obras que anota en su bitácora los celemines de argamasa que precisa un arco de punto.

Pero su vida, no tan pacífica, viene a resultar tan asombrosa como sus libros. Cuando decide empezar a escribir, ya había conocido las glorias tan engañosas de la política —el cobijo de esa tersa sombra siempre perversa del poder - lo mismo que sus amargas decepciones. Y no sólo eso. Un panfleto que por inútil precaución no firmó, El medio más rápido de acabar con los disidentes, enderezado contra el teólogo de la iglesia anglicana Sacheverell, fue causa de que lo recluyeran en la temida prisión de Newgate donde no quiso desperdiciar el tiempo que dedicaba en zaherir a sus enemigos, y escribió otra sátira, el Himno a la picota.

Defoe se decepcionó, por fin, de aquellos que, más encumbrados que él, habían sacado ventaja de sus hojas irónicas, o incendiarias, en las que apuntaló causas políticas que una vez creyó suyas; y llegaron a tanto su melancolía y su disgusto, que sufrió un derrame cerebral, un accidente que no dañó, sin embargo, sus facultades mentales. Ya se ve que no. Logró sobreponerse a las dolencias físicas, y decidió que no haría otra cosa en adelante, sino escribir. Escribir en soledad, escondido de los ojos de sus muchos acreedores, porque murió endeudado hasta la coronilla.

¿Se puede, de verdad, mezclar estos dos oficios, que parecen ser tan ajenos y contradictorios, los de político y escritor? Al hacer yo mismo la pregunta, debo responder con mi propia vida. En un país como Nicaragua, como en cualquier otro de la América Latina, el peso de la acción pública se vuelve insoslayable en la vida de un adolescente, aunque ese adolescente quiera ser escritor. Cuando a los diecisiete años emprendí el viaje desde mi pueblo natal,

1 Lección Inaugural. Dictada en la Universidad Centroamericana (UCA) el 12 de marzo de 2008. 
Masatepe, de la mano de mi padre, hacia la ciudad de León para matricularme en la escuela de derecho, él, que venía de una familia de músicos pobres, se preparaba de alguna manera para entregarme a la vida pública. Quería que fuera abogado, y los abogados han sido tradicionalmente los que conducen la vida política, no sólo los litigios en los tribunales. Son los oradores, los tribunos, los ministros, los legisladores, los presidentes; y de alguna manera, intelectuales en la primera fila de los acontecimientos.

Pero era la Nicaragua de los Somoza, una familia impuesta en el poder por la intervención militar de los Estados Unidos, y que para entonces llevaba ya más de veinte años de mando. La idea de la política que mi padre tenía estaba ligada a la permanencia inmutable de aquella dinastía que de acuerdo a las cuentas que él hacía, no tendría fin. Cuando yo llegué a la universidad, y me quedé allí solo, en un mundo nuevo, comencé a entender que la vida era diferente. Había agitación en las calles, bandadas de estudiantes se lanzaban a protestar casi todos los días contra la dictadura. Y ese mismo año de mi llegada a la universidad, a los pocos meses, la tarde del 23 de julio de 1959, un pelotón de soldados disparó contra nosotros. Nosotros, digo, porque pronto yo estaba ya en la calle protestando. Hubo, fruto de aquella brutalidad insensata, cuatro muertos, dos de ellos mis compañeros de banco en el aula, y más de sesenta heridos.

Era esa Nicaragua de los Somoza que mi padre asumía como natural, la que mi generación quería cambiar de raíz. Éramos, naturalmente, radicales. Ahora solemos olvidar que radical viene de raíz, y no quiere decir más que querer cambiar las cosas desde la raíz. Compromiso solía ser una palabra generosa. Hoy pasa, a veces, por una torpeza, o una falta de razón práctica. Un tributo de los nuevos tiempos a aquella vieja filosofía del liberalismo fundador decimonónico, de que cada quien debe cuidar su parte porque el todo se cuida solo.

Radicales para enfrentarse a un poder matrero, pero implacable que el viejo Somoza, el fundador de la dinastía, había heredado a sus dos hijos, Luis y Anastasio, tras ser muerto a tiros en 1956 por un poeta de 26 años, Rigoberto López Pérez, precisamente en aquella ciudad de León donde yo me entrenaba como revolucionario, y como escritor.

Nací bajo el viejo Anastasio Somoza, fui a la universidad bajo el gobierno de su hijo mayor Luis Somoza Debayle. Me marché a un exilio voluntario bajo ese mismo Somoza, y fue protagonista del derrocamiento del último de ellos, Anastasio Somoza Debayle, que ya preparaba el reinado de su hijo, Anastasio Somoza Portocarrero. Y el 20 de julio de 1979, veinte años después, entramos en triunfo a la Plaza de la Revolución en Managua. El último Somoza, el último marine, había huido, su ejército pretoriano se había desbandado. El poder había sido conquistado por una generación aguerrida, que no estaba dispuesta a hacer concesiones al pasado. A veces me inquieta el sólo pensar que pude haber nacido demasiado antes, o demasiado después, y haberme perdido así de participar en aquella vorágine que me cambió para siempre, como digo en mi libro de memorias Adiós Muchachos: Fue el mejor de los tiempos, fue el peor de los tiempos; fue tiempo de sabiduría, fue tiempo de locura; fue una época de fe, fue una época de incredulidad; fue una temporada de fulgor, fue una temporada de tinieblas; fue la primavera de la esperanza, fue el invierno de la desesperación, según empieza diciendo Charles Dickens en su novela Historia de dos ciudades. 
José Saramago ha dicho alguna vez que no cree en el papel del escritor como misionero de una causa, pero que de todos modos éste tiene deberes ciudadanos. Hace poco le escuché decir, en un encuentro celebrado en Santillana del Mar, en España, y dedicado a su propia obra y a la de Carlos Fuentes y Juan Goytisolo, que lo que se exige del escritor en cuanto a semejantes deberes, se parece al "cuaderno de encargos", en el que los albañiles llevan la cuenta de lo que deben hacer cada día. Julien Green, en el diario del último año de su vida, Le grand large du soir (1997-1998), se refiere a unas anotaciones del cuaderno de encargos de un restaurador suizo en 1873, comisionado para reparar un fresco en el techo de una iglesia de Boswil, en Aargau:

Modificar y barnizar el séptimo mandamiento: 3.45 francos. Ensanchar el cielo y ajustar algunas estrellas; mejorar el fuego del infierno y darle al diablo un aspecto razonable: 3.86 francos.

Retroceder el fin del mundo, ya que se halla demasiado próximo: 4.48 francos.

Modificar los mandamientos, ensanchar el cielo y ajustar las estrellas, atizar las llamas del infierno, disfrazar al diablo con las vestiduras de un pastor de ovejas, retardar el fin del mundo. Ni más ni menos. Un cuaderno de encargos como el que también llevaba Voltaire.

Cuando Voltaire fracasó en su quimera de reformar el poder monárquico, para que la razón terminar de brillar con todas sus luces — no en balde aquel era el siglo de las luces, y aquella debía ser la era de la razón total - se dedicó con fervor a la causa de la defensa de los ciudadanos, escribiendo la asombrosa cantidad de 18.000 cartas, publicadas muchos después de su muerte en 89 volúmenes. En ellas combatía las injusticia, los abusos de poder, denunciaba las sentencias judiciales emitidas bajo precio, la corrupción de los funcionarios; lo que hoy en día llamaríamos un onbusman. Si fuera contemporáneo nuestro, Voltaire tendría un blog.

Esa experiencia compartida, la del intelectual y político, viene de muy atrás en la tradición de la vida pública de América Latina. Y alguna vez fue también una tradición europea. Francis Bacon fue Lord Canciller del rey Jaime I; John Milton, secretario del Consejo de Estado durante el gobierno de Cronwell; preso tras la restauración, Milton tuvo tiempo suficiente en la cárcel para dedicarse a terminar El paraíso perdido, una de las obras capitales de la literatura universal.

Y una tradición española. Don Benito Pérez Galdós no sólo demostró que le concernía la historia al escribir sus Episodios Nacionales, sino la política viva, porque se adhirió al Partido Republicano, y pronunció discursos en contra de la monarquía y del clero desde su asiento de diputado de la coalición republicano-socialista; y aún más, creía en el poder regenerador de la literatura; así nos dice, hablando de su pieza teatral Electra: en Electra puede decirse que he condensado la obra de mi vida, mi amor a la verdad, mi lucha contra la superstición y el fanatismo y la necesidad de que, olvidando nuestro desgraciado país las rutinas, convencionalismos y mentiras, que nos deshonran y envilecen ante el mundo civilizado, pueda realizarse la transformación de una España nueva que, apoyada en la ciencia y la justicia, pueda resistir las violencias de la fuerza bruta y las sugestiones insidiosas y malvadas sobre las conciencias. 
Y don Manuel Azaña, escritor, orador, periodista, presidente de la república española, que fue como ser presidente de un sueño perdido en un mar de sangre. Y también Rafael Alberti, diputado comunista ante Las Cortes, para los tiempos de la transición hacia la democracia al final del franquismo, un símbolo político como Pablo Neruda, que fue también senador por el Partido Comunista de Chile, y candidato simbólico a la presidencia.

El novelista André Malraux, que luchó del lado de la república en España, hombre de acción, fue el paradigma de eso que llamaríamos más tarde "el internacionalista", un tanto en la tradición romántica de Stendhal, internacionalista también bajo las banderas napoleónicas en Europa, no importaba que Napoleón reprendiera a los oficiales de su ejército por dedicarse a la vana distracción de leer novelas en los campamentos, en lugar de aleccionarse en los libros de historia. Pero Malraux terminó congelado en la inmovilidad oficial que depara el poder; y vuelvo aquí al dicho de su amigo Julián Green, que lo describe solitario en los corredores sombríos y desiertos de su ministerio de Cultura en el Palais Royal: "aquel que estuvo siempre por la acción, se hallaba ahora recluido en su pasado por su fidelidad a De Gaulle”.

Los escritores de Estados Unidos, tan lejos del poder, y tan ajenos a la política, si alguna vez se presentan de candidatos, son vistos como rarezas excéntricas: Upton Sinclair, que había escrito La Jungla, perdió las elecciones porque su adversario, poco honesto como tantas veces en las campañas políticas, hacía que se leyeran por la radio párrafos de sus novelas donde sus personajes hablaban mal de la iglesia, de los partidos, y hasta de los boyscouts. O Norman Mailer, derrotado como candidato a alcalde de Nueva York, o Gore Vidal, oveja negra de una familia de patricios, varias veces candidato perdedor a senador. Cuando hay en Estados Unidos un presidente que no desprecia a los escritores, ni los considera peligrosos, los reúne en la Casa Blanca en alguna velada singular, para darse un baño de intelecto. Pero los escritores jamás han sido "inquilinos de la Casa Blanca", como se dice en la jerga política. Nunca han tenido el poder.

Pese a todo lo dicho, el General Lewis Wallace, perteneciente a la Union Army, y Gobernador del territorio de Nuevo México, fue quien escribió la popular novela Ben Hur a finales de los años setenta en el siglo pasado, no sé si para gloria de las armas, o de las letras.

Y siempre hubo en Alemania una filosofía secular detrás de la literatura, capaz de interpretar los grandes oleajes de la historia, y los sacudimientos que se oleaje produce en el alma de los seres humanos. Nadie más alejado de la imagen del político que aturde con sus discursos, que Henrich Böll, un ermitaño rebelde al establishment político, un inconforme sin concesiones, enemigo hasta su muerte de toda manifestación terrenal de poder. El profeta que guiaba a quienes volvían de las trincheras durante la Segunda Guerra Mundial, a encontrarse con su destino en ruinas.

¿Pero Goethe, el genio que escribió Fausto? Goethe fue consejero secreto de Carlos Augusto, duque de Weimar. Era un ducado pequeño, pero él perteneció al aparato de poder, y ahora hay quienes ponen en su cuenta no pocos abusos, como la venta de prisioneros a Inglaterra, ladronzuelos y vagabundos, para que sirvieran de mercenarios en la lucha contra los revolucionarios que buscaban la independencia de Estados Unidos. Parece una calumnia, 
un chismorreo que brota de los túneles de la historia, pero se han escrito libros sobre este Goethe tan desconocido, el consejero secreto, metido en las entrañas del poder, que siempre son oscuras.

Los escritores alemanes han tenido el poder singular, o la pretensión, de ser jueces de la historia de su país, o sus visionarios. Thomas Mann, exiliado en los años siniestros del nazismo. Y Günter Grass, capaz de obligar a la sociedad alemana a mirarse en un espejo irritante que les devuelve el rostro que no quiere, "el Spateraufklärer”, como se llama a sí mismo: el visionario tardío, el último apóstol de una era falta de razón, que ahora se sacude, con algo desdén, el lodo que salpica su uniforme de miembros de las Waffen-SS, que vistió de adolescente.

Por vivir en las entrañas del poder, o a su sombra, siempre se paga un precio. Bacon fue juzgado bajo la acusación de enriquecimiento ilícito, y despojado de su cargo de Lord Canciller; Milton tuvo que defender públicamente las acciones más infames de Cronwell, incluyendo las masacres de Irlanda. Fue whig, y fue tory, balanceándose en el trapecio, de izquierda a derecha. Y también fue agente secreto al servicio de la causa de la unificación de Escocia con Inglaterra, como lo había sido Christopher Marlowe, el poeta contemporáneo de Shakespeare, quien, para el tiempo en que murió asesinado en una reyerta de cantina, figuraba inscrito en la planilla de Sir Francis Walsingham, jefe de los servicios de espionaje de Isabel I. Espía, como el poeta William Wordsworth, a su tiempo admirador de la revolución francesa, y más tarde comprometido en misiones de espionaje en Alemania.

En América Latina, la acción política, sobre todo aquella que se propone una voluntad transformadora, ha comprometido a los intelectuales desde los tiempos de las luchas por la independencia, y ese papel nunca ha dejado de tener congruencia. Pienso en Antonio José de Irisarri, el criollo guatemalteco que escribió novelas satíricas como laHistoria del perínclito Epaminondas del Cauca por el bachiller Hilario de Altagumea, un aventurero radical, y conspirador de oficio, que fue canciller del gobierno del general Bernardo $\mathrm{O}^{\prime}$ Higgins en Chile, y luego prófugo tras ser condenado a muerte, por lo que regresó a la Centroamérica olvidada, desde entonces un traspatio de ruidos confusos.

Pero pienso, sobre todo, en Domingo Faustino Sarmiento, presidente de Argentina, que desde una visión política y a la vez literaria, hombre de poder y hombre de letras, creó a través de su novela Facundo el mito de civilización y barbarie en América, una dualidad que todavía nos aturde.

Facundo Quiroga, caudillo de La Rioja, capitán de montoneras, personaje de la novela, es el gaucho, el habitante de las pampas ya diezmado que se disuelve en la leyenda, pero mestizo cercano y concreto, un mestizo salvaje. Y la barbarie que representa Facundo debe ser sustituida por el ideal civilizador de inspiración europea. Es la visión de John Fenimor Cooper en El Ultimo Mohicano, el choque de indios contra europeos donde estos últimos resultan triunfantes porque son los mejor dotados, en la más pura línea del darwinismo social. El progreso civilizador americano pasaba necesariamente por esta dilucidación; y la raza vencedora del salvaje era europea, ni siquiera mestiza, en los Estados Unidos y en Argentina. 
Pero el intelectual que es hombre de acción en América, tiene necesariamente una visión ecuménica desde los tiempos de la independencia, como es el caso de Baltasar Bustos, el personaje de la novela La Campaña de Carlos Fuentes. Es el hombre ilustrado que peleará toda las guerras de la independencia de uno a otros confín, desde Buenos Aires, a Santiago, a Lima, a Caracas, a Veracruz, siempre en busca de Simón Bolívar, el mítico libertador, y en busca también de una mujer, Ofelia Salamanca, quien, en la gran alegoría de la escritura de Fuentes, seguirá siendo la América nunca encontrada, la libertad que huye y se multiplica en espejismos, y que, como doña Bárbara, seguirá siendo el espacio rural sin conquistar. Otra vez, el viejo dilema entre civilización y barbarie planteado por Sarmiento.

Y José Martí. Cuando se encuentra con Rubén Darío el 24 de mayo de 1893 en el Hardman Hall de Nueva York, la única vez que se vieron durante sus vidas, Darío tiene apenas 26 años, y Martí 40, lo suficiente para que lo llame hijo al abrazarlo. Ambos han vivido ya intensamente, han rebasado la copa de la amargura, han pasado por desengaños y frustraciones. Darío, con su vida familiar hecha pedazos, ya viudo. Martí, bregando por mantener unido al Partido Revolucionario Cubano, para hacer posible la independencia de su patria. Nada es fácil para ninguno de los dos.

En aquel mitin de Hardman Hall, en que Darío lo acompaña como invitado de honor, Martí tendría que enfrentarse a las amargas disensiones de la política, a quienes buscaban dividir, por ambiciones, a las fuerzas independentistas: "Martí tenía esa noche que defenderse. Había sido acusado; no tengo presente ya si de negligencia o precipitación en no sé cuál movimiento de invasión a Cuba. Es el caso que el núcleo de la colonia le era en aquellos momentos contrario", dice Darío. Pero salió airoso Martí, porque seducía con su palabra, un político que era un poeta, rara ave de una floresta hostil, llena de lobos.

Dos años después, el 19 de mayo de 1895, Martí caería en Dos Ríos, al apenas subir al caballo. Y subió al caballo porque el general Máximo Gómez lo había dejado sin ningún papel militar en los combates que se estaban librando en contra de las tropas españolas, y se sintió humillado. ¿Alguna vez han creído los caudillos en los intelectuales?

Darío jamás habría de perdonarle aquel acto supremo de heroísmo, nunca dejaría de lamentar la muerte de aquel hombre que se lanzó solo al combate. Era un raro. En Los Raros Darío traza su retrato dolido, y no le otorga perdón al intelectual caído, que nunca vistió uniforme militar: "Y ahora, maestro y autor y amigo, perdona que te guardemos rencor los que te amábamos y admirábamos, por haber ido a exponer y a perder el tesoro de tu talento. Ya sabrá el mundo lo que tú eras, pues la justicia de Dios es infinita y señala a cada cual su legítima gloria", dice... "Cuba quizás tarde en cumplir contigo como se debe. La juventud americana te saluda y te llora; pero ioh maestro!, ¿qué has hecho?”.

Si los escritores cargamos en América Latina con la pasión de la vida pública, es porque la vida pública tiene entre nosotros una calidad insoslayable. Apartarse de ella sería dejar una oquedad sin fin en el paisaje. No es la vida privada encarnando la historia de las naciones, como pensaba Balzac, sino la vida pública metiéndose en todos los intersticios de la vida privada. Los escritores llegan a convertirse en cronistas iluminados de la historia, y también en jueces implacables de la historia, compuesta al mismo tiempo de episodios inagotables que nunca dejarán de ser un depósito de materiales para el novelista, hazañas y episodios 
olvidados, personajes de extraña singularidad, injusticias sin fondo. Es al novelista a quien toca exhumarlos para volverlos a la vida.

La pasión crítica. El escritor apasionado de los hechos de la vida pública, pendiente de la suerte de las naciones y de quienes las habitan, pendiente de la opresión, y de los desmanes del poder arbitrario; una pasión que anduvo a caballo por los caminos de la independencia cuando los próceres eran filósofos y eran letrados que cargaban La Nueva Eloisa en sus alforjas de campaña, y leían a Tocqueville en los altos de la marcha, como el general Francisco Morazán; no pocos de ellos luego caudillos que olvidaron sus letras y sus sueños libertarios porque el poder no quiere estorbos de conciencia, aún cuando se trate de ejecutar el progreso.

Los próceres que se subieron a los caballos lo eran todo a la vez, como buenos enciclopedistas. Eran una conjunción y resumen de oficios: estrategas militares, filósofos iluministas, ideólogos liberales, doctrinarios masones, juristas imaginativos, legisladores osados, tribunos de salón y oradores de barricada, periodistas de hojas panfletarias, curas rebeldes a los cánones a veces, a veces terratenientes arruinados, a veces comerciantes encandilados por la libertad de comercio, a veces aristócratas en rebeldía. Escribían, además de proclamas, odas y sonetos. Son el todo creador, antes de que cada parte ciudadana reclame su especificidad y el todo se descomponga en sus partes insidiosas, y los actores revolucionarios se enfrenten entre ellos mismos en inquinas y disensiones, y de las quimeras magníficas de unidad se pase a las burdas fragmentaciones de territorios independientes.

Eran jóvenes díscolos y radicales, hijos de obras prohibidas, filosofía y novelas, que entraban de contrabando escondidas en barriles de harina, y porque se trataba de ejemplares tan escasos había quienes las copiaban a mano en los mismos libros en cuarto mayor forrados con lona marinera, donde transcribían también su correspondencia y llevaban sus cuentas, y aún la lista de la ropa sucia a entregar a las lavanderas. Hijos, por tanto, de ideas que causaban estragos y eran vistas como disolventes, enemigas de la monarquía absoluta y de la fe guardada por el Santo Tribunal del Santo Oficio, que sustentaba a la monarquía. Ideas acusadas de foráneas, con lo que se quería hacer ver que no tenían que ver con la realidad interna que hasta entonces nadie perturbaba. Ideas liberales, subversoras del poder de la aristocracia terrateniente y del clero dueño de los privilegios del régimen de propiedad de manos muertas, un término éste que parece inofensivo por inerme, pero que implicaba la acumulación de un inmenso poder económico por parte de la jerarquía eclesial. Y la francmasonería, donde militaban los sediciosos, era una internacional de conspiradores, una hermandad clandestina. Ideas, en fin, exóticas.

Ideas trasplantadas a América con todo y los símbolos que las encarnaban. Véase sino el gorro frigio de los sans-coulotte de las barricadas de la revolución francesa, que quedó extraviado en los escudos de armas de las nuevas repúblicas, desde Argentina hasta Nicaragua, ya metido en el nuevo paisaje, porque en el escudo de Nicaragua el gorro frigio fue sembrado en un palo encima de la cordillera de cinco volcanes, como sobre una barricada, uno por cada pobre e indefensa nueva nación centroamericana. El gorro frigio rojo sangre, como después la hoz y el martillo. Y lo aires tropicales se llenaron, ya se sabe, de los acordes de los himnos nacionales republicanos que copiaban en sus acordes marciales a La Marsellesa. 
Yo me reconozco en la calidad doble del intelectual que imagina y también piensa, que inventa y a la vez predica, que no pone freno a la creación, pero tampoco a la calidad ética de su escritura, una calidad que viene desde aquellos intelectuales ilustrados de la época de la independencia, que también eran escritores y filósofos, y que tanto tuvieron que ver con las ideas que engendraron las lucha libertarias. El escritor que como Voltaire, o como Saramago, o como Fuentes, no deja nunca de estar pendiente de los temas ciudadanos, o el escritor como ciudadano que siempre está obligado a denunciar las situaciones de injusticia, porque para eso se lleva su cuaderno de encargos.

Esto quiere decir, que de no tratarse de una revolución dispuesta a sacudir desde sus cimientos una sociedad injusta, como la que ocurrió en Nicaragua, y dispuesta a derribar un poder obsceno y sanguinario, nunca me hubiera sentido atraído por la política.

Una revolución, que es un momento de llamado a filas, cuando muchos dejan sus oficios habituales, abandonan los escenarios de la vida común y pasan a otro distinto, e inesperado, que cambia para siempre sus vidas, y las marca. El gran poeta nicaragüense Salomón de la Selva, que peleó en la I Guerra Mundial bajo la bandera de Inglaterra, lo dice mejor en Vergüenza, uno de sus poemas del libro El soldado desconocido:

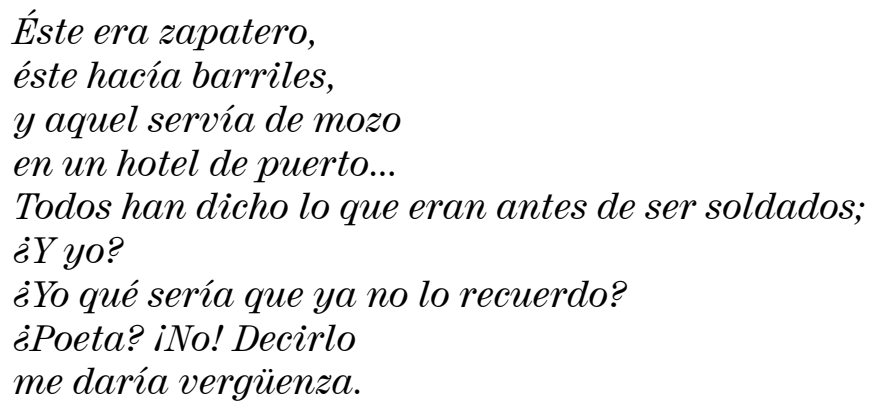

Mi experiencia en la revolución fue una experiencia insustituible. Pero al fin y al cabo, una experiencia de poder. Otros escritores, tuvieron menos fortuna con el poder, cuando lo buscaron. ARómulo Gallegos, electo presidente de Venezuela en 1948, por el prestigio de haber escrito Doña Bárbara, lo derrocaron a los nueve meses los militares de polainas lustradas que parecían salidos de las páginas de Canaima, para los tiempos en que barbarie y jungla eran sinónimos en la literatura. Gallegos pretendía aplicar desde el poder un proyecto de reforma de la sociedad venezolana, tan rural y cerril todavía, como el que Santos Luzardo, el personaje de Doña Bárbara, quería aplicar en el mundo feudal de los llanos ganaderos del Apure. Pero a los militares no les bastó con derrocar a un escritor ilustre. Pocos años después, el dictador General Marcos Pérez Jiménez, uno de los golpistas, encargó a Camilo José Cela, de paso por Caracas, para que escribiera, bajo remuneración, una contraparte de Doña Bárbara. De ese encargo salió una novela llena de falsos venezolanismos que se llamó La Catira.

Es el mismo proyecto de instituciones modernas y democracia representativa que el escritor Juan Bosch quiso que apareciera como por arte de magia en la República Dominicana, al ser electo presidente de manera abrumadora en 1962, tras la caída de la feroz dictadura del 
generalísimo Rafael Leónidas Trujillo, y también a los nueve meses fue derrocado por los militares trujillistas que allí estaban todavía, porque eran demasiado reales para las artes de la magia democrática de Bosch.

Ya se sabe también que a Mario Vargas Llosa lo derrotó en unas elecciones presidenciales un personaje que parece salido de las páginas de La Casa Verde, como aquel inmigrante japonés Fushía que enfermo de lepra viaja en una balsa por el río Marañón, en lo hondo de la Amazonía, para ir a morir al pudridero de la isla de San Pablo. Se trata, como pueden ver, de novelistas que resultan atrapados en los hilos de su propia imaginación. Pero Fujimori, el otro inmigrante japonés que llegó a presidente del Perú, dio paso a un personaje aún más atractivo, Vladimiro Montesinos, todopoderoso jefe de los servicios secretos que guardaba miles de cintas de video donde aparecía él mismo corrompiendo jueces, magistrados, diputados, empresarios, periodistas, militares, siempre un sobre lleno de dinero en su mano mientras las cámaras secretas trabajaban. Allí hay otra novela esperando, La cueva de Montesinos.

Pero Montesinos es un nombre con ecos sombríos, que se repite y se encarna en otros muchos personajes en América Latina. Estamos llenos de Montesinos, prevaricadores cínicos, que, con mejor surte, nunca van a ser sentados todos ellos en el banquillo de los acusados.

Vivimos aún en América Latina una realidad rural, un mundo anacrónico que es contemporáneo y a la vez cercano; y esa dimensión, desolada y esplendorosa, se expresa necesariamente en la imaginación; de lo rural nace eso que tanto se ha llamado realismo mágico. Y lo rural, envuelto en su vieja aura sorprendente, nos persigue aun dentro de las grandes ciudades, como México, Sao Paulo, Buenos Aires o Caracas. Managua, que pese a sus magros adornos de modernidad, es un gran campamento rural. Y el lenguaje latinoamericano de los libros, es todavía, en mucho, el lenguaje elíptico de los cronistas de indias, un lenguaje fruto del asombro frente a lo desconocido que por primera vez se ve, y se toca.

Hay una ambición de volver a contar la historia, o reinventarla, o corregirla. Y para hablar de los asuntos de la vida privada, amor, celos, inquinas traiciones, ambiciones, aún del adulterio, los pasamos siempre por el tamiz de la vida pública, que es su escenario de fondo; es la historia con minúsculas dentro de la Historia con mayúscula.

Eva Perón, la actriz provinciana que termina en la cumbre del poder, y que se encarna como mito en su propio cadáver, es el personaje de un mundo subyacente, que es de todas maneras rural aunque brille con fulgores urbanos, tal como lo describe Tomás Eloy Martínez en su novela Evita. E igual ocurre con Isabel Perón, la bailarina de cabaret que llegar a ser Presidenta de Argentina, y tiene por consejero a un brujo que tira las cartas del Tarot cada mañana para aconsejar las decisiones de estado, y que dispone de su propio escuadrón de la muerte para eliminar a los enemigos señalados por la cábala. Bien podrían ser personajes del Caribe, propios de las consabidas repúblicas bananeras. Y son, en todo caso, personajes de nuestra vida política, y la ficción sólo los copia.

Todo es anacrónico pero contemporáneo, y por lo tanto, real. Sucede, o puede suceder, tanto en Buenos Aires como en Managua, donde el viejo Somoza mandaba en los años cincuenta 
que falsificaran los votos para robarse las elecciones de Miss Nicaragua a favor de su candidata, que a lo mejor era su amante, y en su zoológico doméstico hacía convivir a los prisioneros políticos en jaulas vecinas a las de los leones africanos y las panteras, como lo cuento en mi novela ¿Te dio miedo la sangre?. Historias subyugantes para un novelistas, pero tan terribles para quienes las ha padecido. Entre nosotros, las dimensiones del poder continúan siendo fantasmagóricas, o esperpénticas, como gustaba a Don Manuel del Valle Inclán. Un espejo que sigue multiplicando sus imágenes, no importa que pasen los años o cambiemos de siglo.

No hay que olvidar, tampoco, que muchas veces la Historia contada por los novelistas viene a resultar más definitiva que la contada por los historiadores. El alcalde de Ciénaga, en el departamento de Magdalena, al inaugurar un modesto obelisco en el sitio de la masacre de los trabajadores bananeros ocurrida en 1928, frente a la antigua estación del ferrocarril, episodio que pasó a las páginas de Cien años de soledad, recordó en su discurso a las tres mil víctimas de ese día, un número que sólo está en la novela, en boca de José Arcadio Segundo, y que seguramente nunca llegó a ser tan grande. Pero ahora es una cifra oficial de la Historia.

Haber pasado por la vida pública supone una marca indeleble para un escritor que se aventura más allá de la imaginación y busca alterar la realidad desde los hechos, que es, de todos modos, otra manera de imaginar. Alterar la historia haciéndola, no sólo contándola. Cuando se me pregunta qué me dejó el ejercicio de la política para la literatura, suelo responder que nada. La política, desde el gobierno, se vuelve un asunto de trámites, de agendas, de juegos protocolarios; y sobre todo, de mucha distancia con la gente. Aún en una revolución, los que gobiernan, por la fuerza de la rutina, y de los espacios congelados que crea el poder, van alejándose de la gente y de la realidad circundante. Los filtros palaciegos, las intermediaciones burocráticas, los informes, las cifras, terminan siendo la realidad.

Pero la repuesta es diferente si se refiere al poder. Hay tres temas que son fuente y razón del oficio del escritor, y que están en el título de uno de los libros de cuentos de Horacio Quiroga: el amor, la locura y la muerte; asuntos que Gabriel García Márquez reduce sólo a dos, el amor y la muerte, pero que yo prefiero aumentar a cuatro: el amor, la locura, la muerte, y el poder.

El poder termina modificando la vida de quien lo ejerce, y de los que están colocados bajo su dominio. Es un paisaje circundante que no puede pasar inadvertido, un juego con dados cargados. La gente común, queriéndolo o no, vive dentro de una atmósfera que al cambiar, cambia sus propias vidas, sobre todo cuando los cambios son abruptos, y las vidas se convierten en manos de las viejas Parcas, armadas de poder, en eso que tan simplemente se ha dado en llamar juguetes del destino. El efecto del poder sobre las vidas privadas, he allí la fascinación.

Pero hay otra fascinación en el hecho de ser parte de esa máquina capaz de alterar la vida de las gentes, y poder contarlo luego, contar la manera en que se mueven sus bielas y funcionan sus poleas y engranajes. El raro privilegio de vivir, como testigo y protagonista, en la entraña del poder y conocer desde dentro su sistema digestivo. Y además de que el poder de una revolución tiene atributos de cataclismo, de todas maneras es el mismo poder 
de siempre, el mismo de hace por lo menos diez mil años, con sus reglas ciegas, sus juegos, sus seducciones, su sensualidad, su erótica, vicios, liviandades, miserias y secretos.

Noam Chomsky, uno de los estadounidenses más lúcidos de este siglo, dice que a pesar de que el ser humano ha venido desarrollando su capacidad científica y tecnológica, sus repuestas frente a la naturaleza, y su dominio sobre ella, en cambio sus pasiones y sus debilidades son las mismas de siempre, las mismas de miles de años atrás. Es por lo que Esquilo, y Sófocles, suenan tan frescos a nuestros oídos. Y sobre todo, cuando en sus dramas nos hablan de las luchas de poder, parece que fueran contemporáneos nuestros, viviendo en Lima, en México, en Bogotá o en Managua.

El poder comienza a deteriorar los ideales que le dieron aliento desde el mismo día en que se asume. Es un ser viviente, y responde a las leyes de la vida, como todo lo que nace, crece y muere. Los ideales, íntegros al principio en toda su virtud romántica, dice Boris Pasternak en Doctor Zhivago, ya pierden algo cuando se transforman en leyes; y cuando esas leyes se aplican, ya pierden mucho más de aquella virtud primigenia. Es la manera en que como escritor he visto el poder, como un fascinante proceso que impulsa, deslumbra, discrimina, y luego enfrenta, y divide. Del otro lado está la búsqueda del consenso, que equilibra y armoniza, y crea la estabilidad democrática; pero una revolución hecha por jóvenes, y nunca hay revoluciones hechas por viejos, difícilmente busca consensos, sobre todo cuando el proyecto transformador se base en el presupuesto de la totalidad. Cambiarlo todo, alterarlo todo.

He aquí la gran contradicción. Una revolución fraguada en su momento, en base a los elementos históricos del momento, en un escenario determinado, y hecha por jóvenes que privilegian los ideales y desprecian los castigos inclementes de la realidad, y que convierten la ideología en una virtud sin fisuras, es necesariamente un proceso radical. No hay, por lo tanto, revoluciones moderadas. Eso haría que las revoluciones nacieran viejas, y ya sería un contrasentido. Es la hora de incendiar el universo, acelerar el cataclismo, magma y lava derretida brotando de la tierra abierta en llamas. Pero el poder, inconmovible como es, cumple sus reglas. Y el poder pensado para siempre, eso que llamamos entonces proyecto histórico, viene a resultar un imposible. Una paradoja en la que uno consume su propia vida.

La política militante es una experiencia de mi vida de escritor. Habrá quienes han tenido una experiencia de escritor en su vida de políticos. Y seguramente por eso de que el escritor ha dominado en mi vida, nunca fui ese animal político de que he oído hablar, que cae y se levanta como si nada, y vuelve a empezar como si nada, la piel de lagarto resistente al filo de cualquier cuchillo. Esos son los que tienen madera de caudillos. En América Latina los caudillos siguen siendo una realidad persistente porque, quiero repetirlo, nuestra cultura sigue teniendo un hondo sustrato rural.

De la política me queda, como a Voltaire, el gusto por el oficio de hombre público, el que siempre quiere opinar mientras haya problemas sobre los que opinar, el espíritu crítico que 
nunca habrá de alejarme del debate. Pero también me queda el gusto por la tolerancia, y la desilusión de las ideas eternas y los credos inviolables, de las verdades para siempre. Me queda el gusto ciudadano, de que habla Saramago.

Y me queda, para siempre, la fe en las utopías. Creo que la sociedad perfecta no es posible, pero nunca dejaré de creer que la justicia, la equidad, y la compasión, son posibles. Que los más pobres tienen derecho a vivir con dignidad, y a sentarse en el banquete de la civilización, a participar del desarrollo tecnológico, y del bienestar, que son dones de toda la humanidad. Esa es la utopía, que volverá triunfante algún día, cuando el péndulo que anda lejos, regrese de su viaje hacia la oscuridad, y el desamparo.

Las torres de la ciudad del sol, brillan siempre a lo lejos. Y por mucha que sea la distancia, uno tiene que verlas siempre como si pudiera tocarlas con la mano.

Imaginar, que es una forma de acercarse a la utopía. 